\title{
Risk factors and the prevention of oral clefts
}

Vera Lúcia Gil-da-Silva-Lopes ${ }^{(a)}$ Isabella Lopes Monlleó(b)

(a) Department of Medical Genetics, Faculty of Medical Sciences, University of Campinas UNICAMP, Campinas, SP, Brazil.

(b) Clinical Genetics Service, University Hospital, Medical Genetics Sector, Faculty of Medicine, Federal University of Alagoas UFAL, Maceió, AL Brazil.
* Paper presented at the "Equity, Social Inclusion and Oral Health Promotion: Major Challenges" International Symposium, Held at the $18^{\text {th }}$ Congress of the Brazilian Association for Oral Health Promotion (Associação Brasileira de Odontologia de Promoção de Saúde - ABOPREV), April 2013, Bauru, SP, Brazil.

Declaration of Interests: The authors certify that they have no commercial or associative interest that represents a conflict of interest in connection with the manuscript.

\section{Corresponding Author:}

Vera Lúcia Gil-da-Silva-Lopes

E-mail:vlopes@fcm.unicamp.br

http://dx.doi.org/10.1590/S1806-83242014.50000008 Epub Feb 12, 2014

Submitted: Sep 08, 2013

Accepted for publication: Dec 10, 2013

Last revision: Jan 17, 2014
Abstract: This article presents general aspects of risk factors and particularities of the management of individuals with oral clefts (OCs). A practical manual of prevention and management of this congenital defect was prepared based on a review of the literature and using data from Brazilian multicenter studies. Since OCs require efforts from all levels of healthcare, the data herein presented permits appropriate follow-up for affected individuals and their families. Also, the recognition of risk factors is crucial for planning and implementing preventive measures at the individual and population levels.

Keywords: Cleft Lip; Cleft Palate; Risk Factors; Primary Prevention; Tertiary Prevention.

\section{Introduction}

Recognition of etiology, risk factors and natural history is essential to define how prevention and treatment should be planned and implemented, as well as to measure the efficacy of such intervention. These issues, associated with the assessment of outcomes and patient satisfaction, form the knowledge base which is critical for developing sensible and equitable healthcare policies.

Oral clefts (OCs) are a heterogeneous and important group of congenital defects with prevalence of 1:600-1,000 among newborns. ${ }^{1}$ It includes syndromic and non-syndromic cleft lip (CL), cleft palate (CP) and cleft lip and palate (CLP). OCs are an etiologically heterogeneous group. Approximately $70 \%$ of the cases are isolated (non-syndromic) with etiologic complexity, involving several genetic and environmental risk factors, following a multifactorial threshold model of inheritance. In this situation, familial recurrence is often present and family history should be carefully investigated.

Laboratory facilities have improved the rate of specific diagnosis, and more than 600 syndromes involving OCs have already been recognized. ${ }^{2,3,4,5,6}$ Mental retardation and association with other congenital defects are often seen in this group, in which chromosomal aberrations are the most frequent etiology. Among them, the 22q11.2 deletion syndrome deserves special attention, since the phenotype is heterogeneous and changes with age. ${ }^{7}$

Mendelian/heterogeneous abnormalities and teratogenic factors are the next most prevalent etiologies. ${ }^{8,9,10,11}$ Teratogenic agents are important and preventable factors for congenital defects in general. 
Despite all the available technologies, around $50 \%$ of patients with syndromic OCs represent cases of multiple congenital anomalies without any identifiable etiological factor. ${ }^{6,8,9,10,11}$

The World Health Organization $(\mathrm{WHO})^{12}$ acknowledges that OCs require investment in public policies, in view of their high prevalence, their association with other congenital defects and co-morbidities and their need for prolonged treatment that requires efforts from all levels of healthcare.

Considering the potential for prevention at the population and individual levels, this article describes general aspects of risk factors and particularities of the management of OCs.

\section{Prevention}

In OCs, the preventive approach can be related to two different strategies:

- education of the population about risk factors and

- genetic counseling for families (or individuals) at risk.

Most risk factors can be recognized during family planning and prenatal consultations. Families who receive diagnosis and guidance before or during the prenatal period have the opportunity to seek information and treatment earlier. ${ }^{13}$

The common risk factors are discussed below.

\section{Lifestyle, maternal illness, nutrition and environmental factors}

With regard to OCs, maternal exposure to tobacco and alcohol use, metabolic status (diabetes, obesity or low weight), viral infection, medicinal drugs (anticonvulsants) and teratogens (solvents, agricultural chemicals), as well as the preventive role of vitamin supplements, have been investigated. Maternal smoking during pregnancy is consistently linked with increased risk of OCs, and second-hand smoking has been investigated as well. Findings on the other risk factors and gene-environment interactions have been inconclusive due to methodological issues. ${ }^{3,4,5}$

In order to educate the population and health professionals, recommendations for healthy pregnancies have been made. ${ }^{14,15}$

\section{Parental age}

A meta-analysis approach of parental age showed that fathers 40 years or older have a $58 \%$ higher probability of having a child with cleft palate (CP); for mothers over 40 years of age, the probability is $28 \%$ higher for CP and $56 \%$ higher for CLP. ${ }^{16}$

\section{Consanguinity and recurrence}

It has been suggested that there is a greater genetic component in the etiology of CL based on the observation of an excess of individuals with CL over CLP in the offspring of consanguineous parents. ${ }^{17}$

A population-based study conducted in Denmark showed that anatomical severity does have an effect on recurrence in first-degree relatives, and the type of cleft is predictive of the recurrence type. Third-degree relatives also have an increased recurrence risk compared to the background population. ${ }^{2}$

Genetic evaluation and counseling is needed for virtually all patients with OCs because of its heterogeneous etiology and significant association with minor and major defects. ${ }^{5,18}$ Furthermore, the importance of accurate and detailed phenotype descriptions of OCs to produce good etiological and epidemiological studies has recently been emphasized. In this regard, attention should be given to subphenotypic features of the lip (completeness of the cleft, presence of pits/prints, dental and orbicularis oris muscle anomalies) and palate (completeness of the cleft, submucous defects, bifid uvula and ankyloglossia). ${ }^{3}$

Also, identification of the etiology of a syndromic OC would help management of the patient and prevention for the entire family.

\section{Clinical management Specialized treatment}

Multidisciplinary specialized care has been considered state of the art for treatment of OCs. ${ }^{1}$ It is long-lasting and dependent on surgical correction. When postponed, it increases morbidity and impairs the child's development. ${ }^{13,19}$ In addition, orthodontics and speech therapy are usually indicated, depending on the severity of the cleft.

The affected child should be closely followed and monitored to detect feeding difficulties, the presence 
of other congenital defects, co-morbidities and nutritional failure.

\section{Feeding difficulties}

Insufficient suction, regurgitation of milk into the nasal cavity, ingestion of insufficient amounts of food and, in special situations, aspirations are described for babies with OC. ${ }^{20,21}$ These disorders need to be addressed quickly to ensure that nutritional needs are met and to avoid or minimize the related complications. ${ }^{1,22}$

Feeding should promote efficient caloric support for growth and development and for appropriate weight gain for surgical correction at the expected time. ${ }^{23,24}$ Recommendations and reviews have been published regarding methods and resources for different types of cleft. ${ }^{22,25,26,27}$ Notwithstanding, inadequate feeding is still a common problem. . $^{13,24,28,29,30,31}$

A high rate of adherence to appropriate feeding and adequate growth is related to systematic monitoring of patients. ${ }^{31}$ The lack of follow-up after maternity discharge is particularly relevant and is reflected in nutritional problems. ${ }^{26,28,29,30,32}$ The data indicates the need for public policies for longitudinal follow-up for babies with OC in primary care. ${ }^{26}$

\section{Nutrition}

Several reports emphasize the importance of the nutritional aspects related to postponement of OC surgical repair. ${ }^{13,28,29,32,33}$ Mainly, low weight gain and anemia, which should be preventable. ${ }^{34}$

Although there are reports in the literature on the possibility of breastfeeding with any type of cleft, studies with adequate levels of evidence show that, unlike isolated CL, many patients with CP or CLP can only get breast milk through pumping methods. ${ }^{35,36}$

The nutritional approach is essential for planning treatment. Orientation regarding feeding methods at birth and longitudinal follow-up are important. The encouragement of breastfeeding and, when that is not possible, the use of breast milk and the prevention and treatment of anemia should be priorities. ${ }^{34}$

\section{Co-morbidities}

Secondarily to facial abnormalities, children with OC are subject to several complications, such as oti- tis, pneumonia, oral communication disorders and otologic and/or hearing disorders. Emotional and social disturbances are significant and deserve attention from both families and health professionals. ${ }^{37}$

\section{Associated defects}

Prevalence of structural defects in association with OC ranges from $8 \%$ to $75 \%$, and the majority of reports show that $\mathrm{CP}$ has the highest and CL the lowest rates. The orofacial region and cardiovascular, central nervous, and musculoskeletal (including limbs, hands and feet) systems are most commonly involved. Although there are true population differences, methodological factors such as sample source and size, method of ascertainment, inclusion criteria, coding system and case classification account for much of this wide variation. $4,9,11,18,38,39,40,41,42,43,44$

\section{Management by unspecialized health professionals}

Understanding of the needs and particularities of individuals with OC by health professionals is very important, especially considering the high prevalence of this congenital defect. Nevertheless, health professionals' knowledge of OC is relatively low. ${ }^{13,28,29,30,32,33}$

Primary care is an excellent opportunity to reinforce, encourage and monitor dietary guidelines, as well as to prevent co-morbidities. However, it has been observed that healthcare professionals are unaware of how to manage individuals with OC..$^{33}$

A study involving Brazilian students during their last academic year for different health professions detected that their knowledge of OC was not systematized. In addition, in self-evaluations, $96.4 \%$ affirmed that they were not able to perform routine follow-up of an individual with OC in their own area of expertise. This data has not yet been published, but the authors are working on suggestions of topics to be used for training.

\section{Discussion}

OCs require efforts from all levels of healthcare in view of their high prevalence, their association with other congenital defects and co-morbidities and their need for prolonged treatment. In view of 
the complexity of this congenital defect, it has been a challenge to deal with the special needs of individuals with OC during routine healthcare assistance. This is a global problem recognized by the WHO. ${ }^{12}$

This article is intended to help all health professionals understand this complex scenario and provide directions from different perspectives, which could be useful during clinical management.

Recognition of the risk factors and particular health needs of individuals with OC allows the provision of appropriate healthcare. This includes identification of risk factors, preconceptional and prenatal orientation, neonatal assistance for feeding, investigation of associated congenital defects, and follow-up at the primary care level for monitoring of nutrition and prevention of co-morbidities. This approach facilitates specialized treatment at the right time and may decrease the burden of this prevalent congenital defect.

\section{References}

1. Wyszynski DF. Cleft lip and palate: from origin to treatment. New York: Oxford University Press (US); 2002. 518 p.

2. Grosen D, Chevrier C, Skytthe A, Bille C, Molsted K, Sivertsen A, et al. A cohort study of recurrence patterns among more than 54,000 relatives of oral cleft cases in Denmark: support for the multifactorial threshold model of inheritance. J Med Genet. 2010 Mar;47(3):162-8.

3. Dixon MJ, Marazita ML, Beaty TH, Murray JC. Cleft lip and palate: understanding genetic and environmental influences. Nat Rev Genet. 2011 Mar;12(3):167-78.

4. Mossey PA, Little J, Munger RG, Dixon MJ, Shaw WC. Cleft lip and palate. Lancet. 2009 Nov;374(9703):1773-85.

5. Mossey PA, Shaw WC, Munger RG, Murray JC, Murthy J, Little J. Global oral health inequalities: challenges in the prevention and management of orofacial clefts and potential solutions. Adv Dent Res. 2011 May;23(2):247-58.

6. Online Mendelian Inheritance in Man, OMIM ${ }^{\circledast}$ [homepage on the internet]. Baltimore: McKusick-Nathans Institute of Genetic Medicine, Johns Hopkins University; c1966-2013 [cited 2013 May 22]. Available from: http://omim.org/.

7. Monteiro FP, Vieira TP, Sgardioli IC, Molck MC, Damiano AP, Souza J, et al. Defining new guidelines for screening the 22q11.2 deletion based on a clinical and dysmorphologic evaluation of 194 individuals and review of the literature. Eur J Pediatr. 2013 Jul;172(7):927-45.

8. FitzPatrick DR, Raine PA, Boorman JG. Facial clefts in the west of Scotland in the period 1980-1984: epidemiology and genetic diagnoses. J Med Genet. 1994 Feb;31(2):126-9.

\section{Conclusion}

All the risk factors herein described can be identified and orientation can be offered during routine consultations. In addition, clinical management from birth can be improved with knowledge of all related aspects. To this end, training of health professionals should be emphasized.

\section{Acknowledgements}

This article was supported by FAPESP - Fundação de Amparo à Pesquisa do Estado de São Paulo (2003/08959-3) and CNPq - Conselho Nacional de Desenvolvimento Científico e Tecnológico (149600/2010-0), FAPEAL - Fundação de Amparo à Pesquisa do Estado de Alagoas and Fundo de Apoio ao Ensino, à Pesquisa e Extensão - FAEPEX-UNICAMP. VLGSL is supported by CNPq (304455/2012-1).

9. Rittler M, Cosentino V, Lopez-Camelo JS, Murray JC, Wehby $G$, Castilla EE. Associated anomalies among infants with oral clefts at birth and during a 1-year follow-up. Am J Med Genet A. $2011 \mathrm{Jul} ; 155 \mathrm{~A}(7): 1588-96$.

10. Strauss RP, Broder H. Children with cleft lip/palate and mental retardation: a subpopulation of cleft-craniofacial team patients. Cleft Palate Craniofac J. 1993 Nov;30(6):548-56.

11. Tolarova MM, Cervenka J. Classification and birth prevalence of orofacial clefts. Am J Med Genet. 1998 Jan 13;75(2):126-37.

12. World Health Organization [homepage on the internet]. Geneva: World Health Organization; c2012 [cited 2012 Oct 20]. Available from: http://www.who.int/genomics/publications/en/.

13. Amstalden-Mendes LG, Xavier AC, Antunes DK, Ferreira AC, Tonocchi R, Fett-Conte AC, et al. Time of diagnosis of oral clefts: a multicenter study. J Pediatr. 2011 May-Jun;87(3):225-30.

14. Silveira EL. Recommendations for healthy birth and growth: the ten steps revised. Cad Saude Publica. 2008 Oct;24(10):2451.Portuguese.

15. Castilla EE, Lopez-Camelo JS, Paz JE, Orioli IM. Prevencion primaria de los defectos congénitos. Rio de Janeiro: Editora Fiocruz; 1996. Chapter 10, Conclusiones y recomendaciones; p. 141-7.

16. Herkrath AP, Herkrath FJ, Rebelo MA, Vettore MV. Parental age as a risk factor for non-syndromic oral clefts: a metaanalysis. J Dent. 2012 Jan;40(1):3-14.

17. Harville EW, Wilcox AJ, Lie RT, Vindenes H, Abyholm F. Cleft lip and palate versus cleft lip only: are they distinct defects?. Am J Epidemiol. 2005 Sep;162(5):448-53. 
18. Luijsterburg AJ, Vermeij-Keers C. Ten years recording common oral clefts with a new descriptive system. Cleft Palate Craniofac J. 2011 Mar;48(2):173-82.

19. Zarate YA, Martin LJ, Hopkin RJ, Bender PL, Zhang X, Saal HM. Evaluation of growth in patients with isolated cleft lip and/or cleft palate. Pediatrics. 2010 Mar;125(3):e543-9.

20. Campillay PL, Delgado SE, Brescovici SM. Avaliação da alimentação em crianças com fissura de lábio e/ou palato atendidas em um hospital de Porto Alegre. Rev CEFAC. 2010 Mar-Apr;12(2):9.

21. Clarren SK, Anderson B, Wolf LS. Feeding infants with cleft lip, cleft palate, or cleft lip and palate. Cleft Palate Craniofac J. 1987 Jul;24(3):244-9.

22. Amstalden-Mendes LG, Gil-da-Silva-Lopes VL. Fenda de lábio e ou palato: recursos para alimentação antes da correção cirúrgica. Rev Cienc Med (Campinas). 2006 Set-Oct;15(5):437-48.

23. Reid J. A review of feeding interventions for infants with cleft palate. Cleft Palate Craniofac J. 2004 May;41(3):268-78.

24. Amstalden-Mendes LG, Magna LA, Gil-da-Silva-Lopes VL. Neonatal care of infants with cleft lip and/or palate: feeding orientation and evolution of weight gain in a nonspecialized Brazilian hospital. Cleft Palate Craniofac J. 2007 May;44(3):329-34.

25. Bessell A, Hooper L, Shaw WC, Reilly S, Reid J, Glenny AM. Feeding interventions for growth and development in infants with cleft lip, cleft palate or cleft lip and palate. Cochrane Database Syst Rev. 2011 Feb;16(2):CD003315. DOI: 10.1002/14651858.CD003315.pub3.

26. Gil-da-Silva-Lopes VL, Xavier AC, Klein-Antunes D, Ferreira AC, Tonocchi R, Fett-Conte AC, et al. Feeding infants with cleft lip and/or palate in Brazil: suggestions to improve health policy and research. Cleft Palate Craniofac J. 2013 Sep;50(5):577-90. DOI: 10.1597/11-155. 2013 Apr 4. Epub ahead of print.

27. Reilly S, Reid J, Skeat J. ABM clinical protocol \#17: guidelines for breastfeeding infants with cleft lip, cleft palate, or cleft lip and palate. Breastfeed Med. 2007 Dec;2(4):243-50.

28. Gopalakrishna A, Agrawal K. A status report on management of cleft lip and palate in India. Indian J Plast Surg. 2010 Jan;43(1):66-75.

29. Grow JL, Lehman JA. A local perspective on the initial management of children with cleft lip and palate by primary care physicians. Cleft Palate Craniofac J. 2002 Sep;39(5):535-40.

30. Robin NH, Baty H, Franklin J, Guyton FC, Mann J, Woolley $\mathrm{AL}$, et al. The multidisciplinary evaluation and management of cleft lip and palate. South Med J. 2006 Oct;99(10):1111-20.

31. Smedegaard L, Marxen D, Moes J, Glassou EN, Scientsan C. Hospitalization, breast-milk feeding, and growth in infants with cleft palate and cleft lip and palate born in Denmark. Cleft Palate Craniofac J. 2008 Nov;45(6):628-32.

32. Britton KF, McDonald SH, Welbury RR. An investigation into infant feeding in children born with a cleft lip and/or palate in the West of Scotland. Eur Arch Paediatr Dent. 2011 Oct;12(5):250-5.

33. Damiano PC, Tyler MC, Romitti PA, Druschel C, Austin AA, Burnett W, et al. Primary care physician experience with children with oral clefts in three states. Birth Defects Res A Clin Mol Teratol. 2010 Dec;88(12):1050-6.

34. Gil-da-Silva-Lopes VL, Amstalden-Mendes LG, Magna LA, Ribeiro AF, Nogueira RJN. Improving Pre-surgical nutrition for cleft babies based upon a multicenter study. Cleft Palate Craniofac J. Forthcoming 2013.

35. Biancuzzo M. Clinical focus on clefts. Yes! Infants with clefts can breastfeed. AWHONN Lifelines. 1998 Aug;2(4):45-9.

36. Academy of Breastfeeding Medicine Protocol Committee. ABM clinical protocol \#3: hospital guidelines for the use of supplementary feedings in the healthy term breastfed neonate, revised 2009. Breastfeed Med. 2009 Sep;4(3):175-82.

37. Tisza VB, Gumpertz E. The parents' reaction to the birth and early care of children with cleft palate. Pediatrics. 1962 Jul;30:86-90.

38. Beriaghi S, Myers SL, Jensen SA, Kaimal S, Chan CM, Schaefer GB. Cleft lip and palate: association with other congenital malformations. J Clin Pediatr Dent. 2009 Spring;33(3):207-10.

39. Croen LA, Shaw GM, Wasserman CR, Tolarova MM. Racial and ethnic variations in the prevalence of orofacial clefts in California, 1983-1992. Am J Med Genet. 1998 Aug 27;79(1):42-7.

40. Genisca AE, Frias JL, Broussard CS, Honein MA, Lammer EJ, Moore CA, et al. Orofacial clefts in the National Birth Defects Prevention Study, 1997-2004. Am J Med Genet A. 2009 Jun;149A(6):1149-58.

41. Working Group. Prevalence at birth of cleft lip with or without cleft palate. Data from the International Perinatal Database of Typical Oral Clefts (IPDTOC). Cleft Palate Craniofac J. 2011 Jan;48:(1)66-81.

42. Milerad J, Larson O, Hagberg C, Ideberg M. Associated malformations in infants with cleft lip and palate: a prospective, population-based study. Pediatrics. 1997 Aug;100:(2 Pt 1)1806.

43. Shprintzen RJ, Siegel-Sadewitz VL, Amato J, Goldberg RB. Anomalies associated with cleft lip, cleft palate, or both. Am J Med Genet. 1985 Apr;20(4):585-95.

44. Wyszynski DF, Sarkozi A, Czeizel AE. Oral clefts with associated anomalies: methodological issues. Cleft Palate Craniofac J. 2006 Jan;43(1):1-6. 